\title{
SUBCUTANEOUS FAT NECROSIS OF THE NEWBORN
}

\author{
BY \\ A. HOLZEL \\ From the Department of Paediatrics, University of Manchester
}

(Received for Publication March 24, 1950)

In the course of the past year three cases of subcutaneous fat necrosis of the newborn have been seen and followed up. They presented features interesting enough to warrant description, particularly as some of them may help to shed light on the still obscure aetiology of the disease.

\section{Case Reports}

Case 1. A male infant was admitted to hospital on August 4, 1949, at the age of 3 weeks because his mother had noticed a number of small reddish-purple ' lumps' on his thighs during the week preceding his admission. He was the third child of healthy parents, the other children being well. His weight at birth was $9 \mathrm{lb} .2 \mathrm{oz}$. The delivery was normal, labour having lasted 24 hours, but the infant showed signs of asphyxia and required resuscitation. He recovered quickly and was able to feed from the breast in the course of the first 24 hours. Examination on admission showed an infant in good general condition (weight $10 \mathrm{lb} .6 \mathrm{oz}$.). There was slight desquamation of the skin of the abdomen and back. On the flexor aspect of both thighs there was a symmetrically placed indurated area, bluish-red in colour, with a raised edge, extending over the deeper structures of the thigh. The indurated edge seemed to extend about $1 \mathrm{~cm}$. in depth and could be firmly gripped between the examining fingers. Smaller areas of similar appearance were noticed on both calves. Nothing else abnormal could be detected. The temperature was $99 \cdot 2 \mathrm{~F}$.

During the first two days the condition was regarded as an acute inflammatory lesion and was treated with intramuscular penicillin, 100,000 units eight-hourly. However, new areas of induration appeared at the site of the penicillin injections, involving the lateral and extensor aspects of the thighs. Penicillin treatment was therefore discontinued and oral sulphamezathine therapy substituted. A tentative diagnosis of subcutaneous fat necrosis was made at this time.

In the course of the succeeding week new lesions of similar appearance but varying size appeared. The areas now affected were the sacral, the gluteal, the lateral part of the back, and the skin over and below both scapulae. On the eleventh day after admission a biopsy of the skin and the subcutaneous tissues of the left thigh was carried out.

BIOPSY REPORT. An inflammatory reaction was present in the subcutaneous fat, most marked immediately below the dermis but not extending therein, but appearing rather as finger-like processes into the fat. The cellular reaction consisted mostly of large cells with ill-defined cytoplasm and pale oval nuclei (probably histiocytes); a few polymorphs and lymphocytes were present. A number of giant cells could be seen, not of foreign body type but consisting of three or four nuclei in an ill-defined basophilic cytoplasm. The lipid in some of the fat cells included in these areas appeared to have broken down giving rise to fatty acid crystals arranged radially. Arteries penetrating the subcutaneous fat tended to show an acute periarteritis.

The child's general condition remained good, though his temperature showed almost daily fluctuation between $100^{\circ}$ F. and $98 \cdot 8^{\circ}$ F. Towards the end of the fourth week, when some of the indurated areas seemed to be regressing, he was discharged home. His weight had been steadily rising. He was seen in the out-patient department one month later. The involved skin had returned to normal apart from a small area on the extensor aspect of both thighs, but on the lateral surface of the right thigh overlying the trochanter a depressed area was noticeable. This subsequently presented as a deep groove due to atrophy of the subcutaneous fat (Fig. 1). The overlying skin was normal but firmly fixed

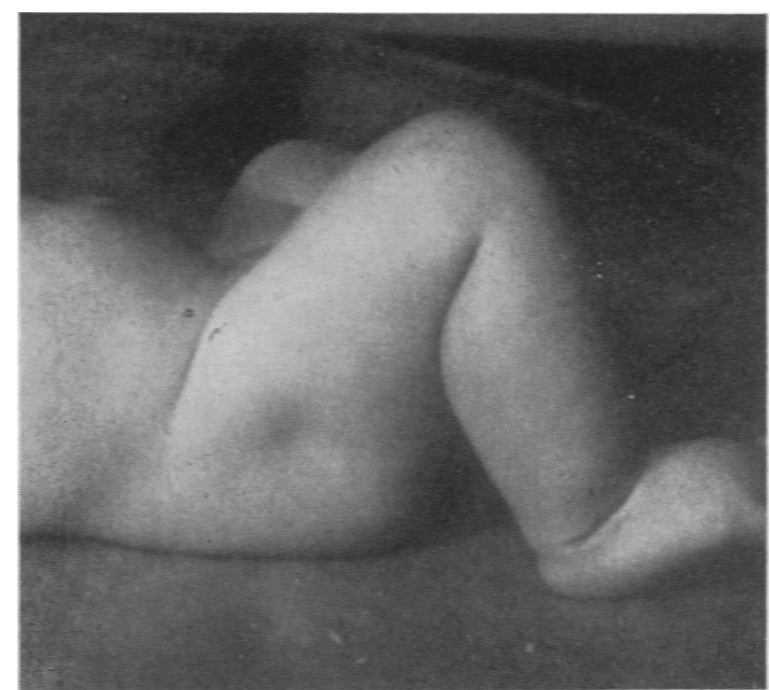

Fig. 1-Atrophy following subcutaneous fat necrosis. 
to the underlying structures. Physical and mental progress had been satisfactory throughout.

Case 2. A boy, aged 2 days, was admitted to hospital because of severe cyanosis which developed shortly after birth. Oxygen was administered and an injection of coramine was given into the thigh. Pregnancy, labour, and delivery had been normal. Birth weight was $7 \mathrm{lb}$.

Examination revealed a well-developed, plump infant, somewhat distressed and with a hoarse cry. The face appeared extremely congested and small petechiae were visible on the forehead and cheeks. Respiration was rapid. The temperature was $101^{\circ} \mathrm{F}$. There was a purulent discharge from the nose and eyes, and a foetid smell, although the infant was perfectly clean. Slight desquamation of the hands and feet was noticed. The percussion note over the right axilla was impaired. No other pathological findings could be elicited. A diagnosis of atelectasis was made and this was confirmed radiologically, the radiograph of the chest also revealing a right-sided pneumothorax.

Penicillin and streptomycin were administered intramuscularly into the thighs for the first three days, when streptomycin was discontinued and penicillin continued by mouth.

During the first few days the infant was kept in an oxygen tent and the cyanosis improved considerably. The temperature returned gradually to normal in the course of the first week. At the beginning of the following week a firm, reddish-purple swelling of the right lower buttock developed, which extended some way into the panniculus adiposus. Three days later a similar indurated area appeared in the other buttock, firmly attached to the skin and showing the 'orange-peel' sign on attempting to lift up a fold of skin. The indurated area was raised slightly above the level of the normal skin, was not tender, and felt rather warmer than the rest of the skin. There was no fluctuation. After three weeks the infant's general condition had greatly improved, the pneumothorax had been absorbed, the atelectatic lung had re-expanded, cyanosis and dyspnoea had disappeared, but the induration of the buttocks still persisted. The gain in weight was satisfactory and the infant was discharged. He was seen regularly at fortnightly intervals, and after approximately two months the induration had completely cleared and the baby appeared well and healthy.

Case 3. A female child was delivered by difficult forceps extraction. Severe asphyxia was present and was treated with lobelin (injected into the cord) and oxygen. The infant responded quickly. The weight at birth was $10 \mathrm{lb}$.

On the twelfth day there appeared a hard, reddened mass on the anterior part of the right upper arm and several smaller reddened and indurated areas like nodules in the skin of the right side of the neck below the mastoid. In the course of the following week three further indurated areas were noticed in the subcutaneous tissue over the right deltoid.

The baby's well-being was not affected, feeds being taken well, and weight gain was adequate. At the end of the third week she was discharged. Two months later the affection of the skin and subcutaneous tissue had entirely disappeared.

\section{Discussion}

Bojlen and Petri (1936), discussing the aetiology of fat necrosis of the newborn, support the prevailing view that birth injury is of major importance (Bernheim-Karrer, 1926; Marfan and Hallez, 1926). Zeek and Madden (1946), summing up the opinions of various authors, give six points regarded as contributory : (1) obstetric trauma; (2) low temperature, causing fat to solidify so that it acts as a foreign body; (3) deficiency of olein in the fat tissue of the newborn, also causing fat to solidify; (4) the presence of an abnormal lipolytic ferment; (5) glandular dyscrasia; and (6) combinations of several of these factors.

Against birth injury being of importance in the aetiology of fat necrosis it is pointed out by Fischl (1931) that obstetric injury is common whereas fat necrosis is certainly rare. Obstetric trauma will not account for its appearance in infants delivered by Caesarean section. Gray (1926) recorded its occurrence antenatally.

Considering the history of the cases reported here, it is striking that each of them was asphyctic at, or shortly after, birth. In Cases 1 and 3 this was due to difficult delivery, whilst in Case 2 it was the result of atelectasis and pneumothorax. It is therefore suggested that anoxaemia resulting from asphyxia may be a predisposing element, though certainly not the only one. Asphyxia was present in Unshelm's (1932) case delivered by Caesarean section, as well as in an infant reported by Woringer and Weiner (1928). The occurrence of asphyxia in utero offers an explanation for those cases reported as having developed the disease before birth.

Among the 14 cases of Scandinavian authors reviewed by Bojlen and Petri (1936) the presence of asphyxia at birth was stressed in more than half of them, but the obstetric data in the remainder are not complete. The patients of Fischl (1931), Kohnstam and Herbert (1927), Zeek and Madden (1946), Flory (1948), Harrison and McNee (1926), Bernheim-Karrer (1926), McIntosh, Waugh, and Ross (1938) also suffered from various degrees of asphyxia. In its wider sense asphyxia can be included among the birth injuries, so that the same objection may be raised against its being of aetiological significance regarding its relative frequency compared with that of fat necrosis in the newborn. It is therefore likely that anoxaemia only prepares the way and that one or more additional factors so far unknown are necessary for the development of the characteristic clinical changes. 
A low-grade pyrexia was encountered in the three cases here reported as well as in a large number of those previously cited. An increase in the white blood cells with polymorphonuclear preponderance was noted in Case 1, persisting beyond the period during which it is physiological. Case 2 showed a leucopenia of 2,000 with $90 \%$ polymorphonuclear cells in the differential count.

Often there is an associated infection, as in Case 2, and those of Fischl, Harrison and McNee, Zeek and Madden, and others. It is possible that fat necrosis is the direct response of adipose tissue, already damaged by anoxaemia, to an infecting agent or is an allergic reaction to a localized infection. Trauma, such as obstetric manipulations or, as in Case 1, penicillin injections, may also be a contributing factor.

The histological picture in Case 1 agrees with the findings of Harrison and McNee, Bojlen and Petri, Zeek and Madden, and Davis and Brain (1947), and indicates an inflammatory reaction mainly in the tissue between the fat lobules. It has been suggested that this may be a response to the necrosed fat acting in the manner of a foreign body.

The low olein content of the fat tissue of the newborn or the correspondingly greater palmitic acid value can hardly be accepted as of aetiological importance, since the findings apply to all newborn infants. No evidence of a lipolytic enzyme has been produced so far, nor has any glandular dyscrasia been encountered.

A case of relapsing febrile nodular non-suppurative panniculitis in a young child was described by Larkin, De Sanctis, and Margulis (1944). The distribution of the lesions was similar to that of fat necrosis of the newborn. Spain and Foley (1944), Ungar (1946), and Mostofi and Engleman (1947) demonstrated that the typical histological changes of Weber-Christian disease were not confined to the subcutaneous panniculus but were to be found throughout the adipose tissue, epicardial, peripancreatic, perirenal, periadrenal, mesenteric, omental and pretracheal fat, being involved. As a further characteristic of Weber-Christian disease, atrophy of the subcutaneous fat with attachment to deeper structures has been pointed out (Johnson and Plice, 1949). Zeek and Madden (1946) and Flory (1948) discovered that fat necrosis in their cases was not limited to the subcutaneous structures but was scattered throughout the fat tissues of the body affecting the perithymic, perirenal, periaortic and peribronchial fat as well as that situated round the ribs, pancreas, and mesentery. Case 1 showed a marked degree of atrophy of the fat tissue similar to that reported in the cases of Weber-Christian disease, only it was more pronounced.
Though histologically the fat tissues in nodular panniculitis show a more extensive cellular infiltration and the inflammatory process is more active than in fat necrosis, they are essentially similar. No fat crystals have been found in panniculitis, but this may be a reaction peculiar to the fat tissues of the newborn, due to its different composition. Harrison and McNee (1926) have expressed the opinion that fat necrosis may be a primary inflammation of the adipose tissue, a point of view which is supported by the clinical features of the disease, its febrile course, the association with an increase in the polymorphonuclear cells, the development of new lesions many weeks after birth, its appearance in infants of good general condition, and the similarity to febrile relapsing non-suppurative nodular panniculitis.

\section{Summary}

Three cases of fat necrosis in the newborn are reported, and the various aetiological factors discussed.

Anoxaemia resulting from asphyxia is suggested as the most likely predisposing element.

Fat necrosis of the newborn is regarded as an inflammation of the fat tissues not limited to the subcutaneous panniculus adiposus, and points of similarity with Weber-Christian disease are stressed.

My thanks are due to Professor Wilfrid Gaisford for his most valuable advice and criticism.

REFERENCE:

Bernheim-Karrer, J. (1926). Z. Kinderheilk., 42, 658. Bojlen, K., and Petri, S. (1936). Acta paediatr., Stockh., $19,123$.

Davis, E., and Brain, R. T. (1947). Brit. J. Derm. Syph., 59, 312.

Fischl, R. (1931). Arch. Kinderheilk., 92, 237.

Flory, C. M. (1948). Arch. Path., 45, 278.

Gray, A. M. H. (1926). Arch. Derm. Syph., Chicago, $14,635$.

Harrison, G. A., and McNee, J. W. (1926). Archives of Disease in Childhood, 1, 63, 123.

Johnson, W. A., and Plice, S. G. (1949). Arch. Path., 48, 281.

Kohnstam, G. L. S., and Herbert, F. K. (1927). Archives of Disease in Childhood, 2, 349.

Larkin, V. de P., De Sanctis, A. G., and Margulis, A. E. (1944). Amer. J. Dis. Child., 67, 120.

Marfan, A. B., and Hallez, G. L. (1926). Nourisson, 14, 226.

McIntosh, J. F., Waugh, T. R., and Ross, S. G. (1938). Amer. J. Dis. Child., 55, 112.

Mostof, F. K., and Engleman, E. (1947). Arch. Path., 43, 417.

Siwe, S. A. (1933). Jb. Kinderheilk., 141, 1.

Spain, D. M., and Foley, J. M. (1944). Amer. J. Path., 20, 783.

Ungar, H. (1946). J. Path. Bact., 58, 175.

Unsheim, E. (1932). Mschr. Kinderheilk., 52, 321.

Woringer, P., and Weiner, G. (1928). Rev. franç. Pediat., 4, 57.

Zeek, P., and Madden, E. M. (1946). Arch. Path., 41, 166. 